\title{
Effect of L-arginine infusion on airway NO in cystic fibrosis and primary ciliary dyskinesia syndrome
}

\author{
H. Grasemann*, S.S. Gärtig*, H.G. Wiesemann*, H. Teschler ${ }^{+}$, N. Konietzko, F. Ratjen*
}

\begin{abstract}
Effect of L-arginine infusion on airway NO in cystic fibrosis and primary ciliary dyskinesia syndrome. H. Grasemann, S.S. Gärtig, H.G. Wiesemann, H. Teschler, N. Konietzko, F. Ratjen. (C)ERS Journals Ltd 1999.

ABSTRACT: Airway nitric oxide concentrations in patients with cystic fibrosis or primary ciliary dyskinesia syndrome have been shown to be lower than in healthy subjects. Decreased NO concentrations may contribute to impaired ciliary clearance, respiratory tract infections, or obstructive lung disease in these conditions.

Nasal and exhaled NO concentrations were compared before and after infusion of $500 \mathrm{mg} \cdot \mathrm{kg}^{-1} \mathrm{~L}$-arginine, the substrate of NO synthases, in 11 cystic fibrosis (CF) patients, seven primary ciliary dyskinesia (PCD) syndrome patients, and 11 control subjects.

Baseline nasal and exhaled NO concentrations were significantly lower in both $\mathrm{CF}$ and PCD syndrome patients than in controls $(p<0.01)$. In controls, the maximum increase of NO was seen immediately after L-arginine infusion in the upper airways (1.8-fold) and $3 \mathrm{~h}$ after the infusion in the lower airways (1.4-fold). Although NO concentrations also increased significantly in both $\mathrm{CF}$ (1.9-fold and 1.6-fold, respectively) and PCD syndrome patients (1.4-fold and 1.8-fold, respectively), concentrations remained subnormal compared with baseline values of controls. Pulmonary function remained unchanged in both patient groups.

In conclusion, the low airway nitric oxide formation in both cystic fibrosis and primary ciliary dyskinesia syndrome patients can be augmented by L-arginine administration. The finding that pulmonary function remained unchanged in both conditions may be due to the fact that normalization of airway nitric oxide concentrations could not be achieved.
\end{abstract}

Eur Respir J 1999; 13: 114-118.

*Children's Hospital, and ${ }^{+}$Ruhrlandklinik, University of Essen, Essen, Germany.

Correspondence: F. Ratjen

Zentrum für Kinder-und Jugendmedizin

Universitätsklinikum Essen

Hufelandstr. 55

D-45122 Essen

Germany

Fax: 492017235721

Keywords: Cystic fibrosis

L-arginine

nitric oxide

primary ciliary dyskinesia syndrome

Received: July 91998

Accepted after revision September 141998
Nitric oxide has multiple functions in the airways including regulation of vascular and bronchial tone, host defence, as well as modulation of ciliar motility [1]. Many cells residing within the respiratory tract have the potential to release NO, including endothelial cells, epithelial cells, neutrophils, and alveolar macrophages [2-4]. NO that appears in the exhaled air is derived from endogenous production, but the precise source of expired NO is unknown. While concentrations of exhaled NO are increased in bronchiectasis or asthma [5, 6], there are three known conditions with reduced airway NO concentrations: primary ciliary dyskinesia (PCD) syndrome [7], cystic fibrosis (CF) $[8,9]$, and systemic sclerosis with pulmonary hypertension [10]. PCD syndrome and CF are further characterized by impaired ciliary clearance, pathological retention of airway fluids, recurrent respiratory tract infections, and chronic obstructive lung disease $[11,12]$. The reason for decreased NO formation in CF and PCD syndrome are unknown; airway wall and epithelial lining fluid thickening as diffusion barriers, or limitation of substrate for the nitric oxide synthase (NOS) may be involved.

Airway NO has been shown to modulate bronchomotor tone [13] and the authors recently demonstrated that pulmonary function in CF patients is positively correlated to both lower airway NO [9] and the concentration of sputum
NO metabolites [14]. As NO is a potent bronchodilator, decreased NO formation in advanced CF pulmonary disease could contribute to the obstructive lung disease in these patients. The aim of this study was to assess: 1) whether the decreased NO formation in CF and PCD patients can be augmented by infusion of L-arginine, as indicated by increased NO concentrations in the lower respiratory tract and/or upper airways; and 2) whether stimulation of NO production can improve pulmonary function.

Methods

\section{Subjects}

Eleven patients (six females) with CF were included in this study. The diagnosis of CF was confirmed by repeated sweat tests with chloride concentrations $>60 \mathrm{mmol} \cdot \mathrm{L}^{-1}$. The age range was $11-37$ yrs ( $19 \pm 9$ yrs; mean \pm SD). Mean forced expiratory volume in one second (FEV1) was $47 \pm 20 \%( \pm \mathrm{SD})$ and mean forced vital capacity (FVC) was $56 \pm 19 \%$ predicted, respectively, as assessed by spirometry. All CF patients were admitted to the hospital for an elective $i . v$. antibiotic therapy of 14 days and were studied at the end of their admission. Seven patients (three females) with PCD syndrome were studied. All had been 
diagnosed functionally by nasal biopsies and all but one had situs inversus. The age range was 6-32 yrs (mean $19 \pm 9$ yrs), mean FEV1 was $78 \pm 19 \%$, and FVC was $87 \pm$ $14 \%$ pred. None of the patients received corticosteroids. All patients were instructed not to take any $\beta_{2}$-agonist medication for at least $6 \mathrm{~h}$ prior to investigation. Patients were compared with 11 healthy nonsmoking subjects (seven females), 15-36 yrs of age (mean $25 \pm 5$ yrs). None of the controls had a recent history of respiratory tract infection or was receiving any medication. The study was approved by the human ethics committee of the authors institution. Written informed consent was obtained from each patient and volunteer or their parents, respectively.

\section{Study protocol}

A $21 \%(\mathrm{w} / \mathrm{v})$ L-arginine hydrochloride solution (Braun, Melsungen, Germany) was diluted in $250 \mathrm{mg}$ of normal saline and immediately administered in a peripheral vein in a dose of $0.5 \mathrm{~g} \cdot \mathrm{kg}$ body weight ${ }^{-1}$ over a period of 20 min. Blood pressure and oxygen saturation were monitored during this period and during $30 \mathrm{~min}$ after infusion. NO airway concentrations and pulmonary function were measured before and immediately after the infusion, as well as after $3 \mathrm{~h}$ and $24 \mathrm{~h}$. Serum L-arginine and L-citrulline levels were determined before and after L-arginine administration in 13 patients (nine CF and four PCD syndrome).

\section{Measurement of nitric oxide}

Each subject was asked to perform two manoeuvres which are described in detail below: a slow exhalation after a maximal inspiration for lower airway NO detection, and a breath hold for nasal NO measurement. Each manoeuvre was performed three times with a short rest in between. The mean of the three readings was used for analysis. Preliminary experiments showed no significant loss of NO when flushing the system with a calibration gas of 80 parts per billion (ppb). NO concentrations were recorded on-line using a chemiluminescent analyser (Sievers $280 \mathrm{~A}$, Boulder, CO, USA) at a constant sample gas flow of $1.1 \mathrm{~mL} \cdot \mathrm{s}^{-1}$. The minimal detectable NO concentration was $1 \mathrm{ppb}$. The analyser was calibrated before each study using the 80 ppb NO calibration gas.

\section{Lower airway nitric oxide}

Single-breath measurements were performed to determine the lower airway NO concentration. Each subject was asked to inhale room air to total lung capacity (TLC) and then to exhale slowly to residual volume (RV). The mouthpiece had a $2 \mathrm{~mm}$ diameter open end. This expiratory resistance produces a continuous positive expiratory pressure of approximately $4 \mathrm{cmH}_{2} \mathrm{O}$ in the mouth which closes the velum during expiration and minimizes contamination of air from the lower respiratory tract by upper airway NO [15]. The mouthpiece was connected to the chemiluminescence analyser with a Teflon tube via a side port. NO concentration was assumed to be alveolar when the simultaneously monitored end-tidal carbon dioxide concentration reached a plateau.

\section{Nasal nitric oxide concentration}

A plastic nosepiece was placed inside one nostril of each subject and directly connected to the analyser with a Teflon tube, similar to as previously described [8]. A deep breath was held while the other nostril was manually closed until nasal NO concentration reached a plateau. Plateau concentrations were obtained from both nostrils; and the higher reading was used for analysis.

\section{Pulmonary function testing}

FEV1, and FVC were measured by spirometry (Volugraph, Mijnhardt, Bunnik, the Netherlands). Results were expressed as percentages of predicted reference values [16, 17].

\section{Statistics}

NO concentrations were expressed as either mean value and $95 \%$ confidence interval $(\mathrm{CI})$ or as mean value \pm SEM. All other data are expressed as mean \pm SD. Since not all data were normally distributed, intragroup and intergroup comparisons were performed with the Wilcoxon test. A pvalue $<0.05$ was considered statistically significant.

\section{Results}

One CF patient complained of dizziness after the infusion of L-arginine which resolved spontaneously. Discomfort or unusual taste were not observed by any other patient or volunteer. Blood glucose levels and blood gases remained unchanged before and after the infusion of Larginine (data not shown). Baseline serum L-arginine and L-citrulline concentrations were within the normal range. Changes after infusion are shown in table 1 .

\section{Lower airway NO}

Exhaled NO concentrations from the lower respiratory tract before infusion of L-arginine are displayed in figure 1 . Mean baseline NO concentrations in both CF $(2.3 \pm 1.4$ ppb ( $\pm \mathrm{SD})$; 95\% CI: 1.4-3.1 ppb) and PCD syndrome patients $(2.3 \pm 1.0 ; 95 \% \mathrm{CI}: 1.5-3.0 \mathrm{ppb})$, were significantly lower than in controls $(4.7 \pm 2.2$; $95 \%$ CI: $3.4-5.9 \mathrm{ppb})$, however, there was marked overlap between the groups. Exhaled NO concentration in controls increased significantly

Table 1. - L-arginine and L-citrulline plasma concentrations in cystic fibrosis (CF) $(n=7)$ and primary ciliary dyskinesia (PCD) syndrome $(n=5)$ patients

\begin{tabular}{lcccc}
\hline & \multicolumn{2}{c}{$\mathrm{L}$-arginine $\left(\mu \mathrm{mol} \cdot \mathrm{L}^{-1}\right)$} & \multicolumn{2}{c}{ L-citrulline $\left(\mu \mathrm{mol} \cdot \mathrm{L}^{-1}\right)$} \\
\cline { 2 - 5 } & $\mathrm{CF}$ & $\mathrm{PCD}$ & $\mathrm{CF}$ & $\mathrm{PCD}$ \\
\hline Pre & $108 \pm 10$ & $122 \pm 14$ & $40.6 \pm 4.5$ & $32.2 \pm 3.5$ \\
$20 \mathrm{~min}$ & $7139 \pm 430^{*}$ & $7507 \pm 1042 *$ & $49.7 \pm 6.2$ & $35.4 \pm 4.2$ \\
$3 \mathrm{~h}$ & $434 \pm 72$ & $450 \pm 49$ & $53.0 \pm 5.6$ & $36.0 \pm 7.0$ \\
$24 \mathrm{~h}$ & $156 \pm 32$ & $209 \pm 21$ & $67.5 \pm 2.5$ & $40.0 \pm 2.0$ \\
\hline
\end{tabular}

Data are presented in mean \pm SEM. Normal range for L-arginine plasma concentrations is $20-280 \mu \mathrm{mol} \cdot \mathrm{L}^{-1}$. *: $\mathrm{p}<0.01$ versus baseline (Pre). 


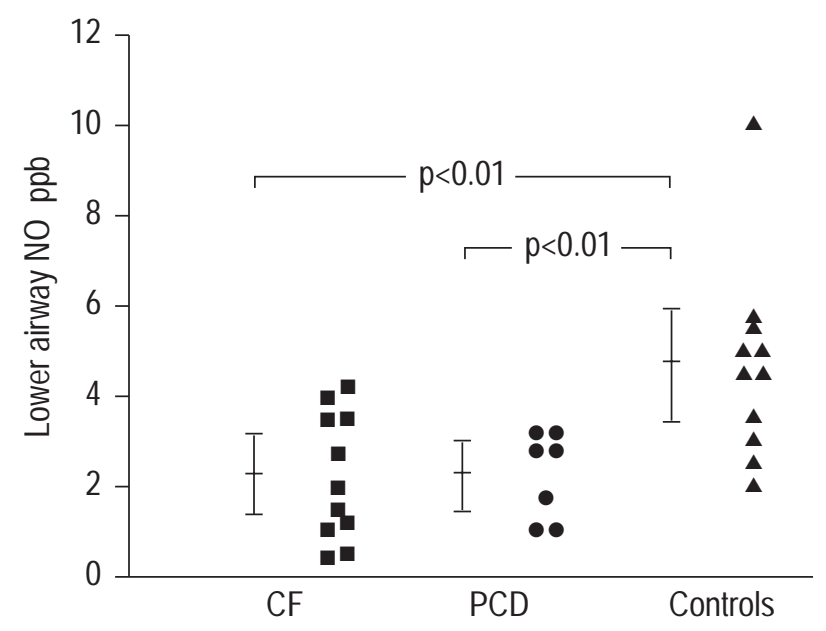

Fig. 1. - Concentrations of exhaled nitric oxide in parts per billion (ppb) in patients with cystic fibrosis (CF), primary ciliary dyskinesia (PCD) syndrome, and controls. Every symbol represents one individual; the horizontal lines are the mean NO and $95 \%$ confidence interval for the population. Concentrations in controls were significantly higher than in both CF and PCD syndrome patients.

20 min following the administration of L-arginine and remained elevated at $3 \mathrm{~h}$ after the infusion (fig. 2). NO returned to baseline values after $24 \mathrm{~h}$. In $\mathrm{CF}$, exhaled NO concentration was also significantly elevated $20 \mathrm{~min}$ and 3 $\mathrm{h}$ after the L-arginine infusion. In PCD syndrome exhaled NO was significantly increased only at $3 \mathrm{~h}$ after L-arginine (fig. 2). When compared with baseline concentrations of controls, lower airway NO concentrations remained subnormal in both CF and PCD syndrome patients.

\section{Upper airway $N O$}

Nasal NO concentrations before L-arginine infusion are displayed in figure 3 . Nasal NO was highest in controls $(1,195.5 \pm 618.2 \mathrm{ppb}( \pm \mathrm{SD})$; 95\% CI: $830.1-1,560.8 \mathrm{ppb})$,

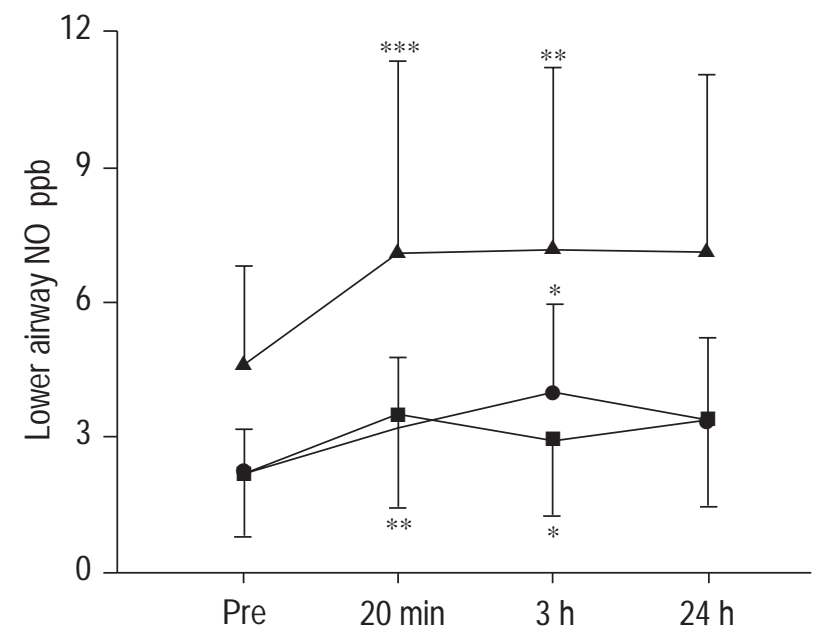

Fig. 2. - Concentrations of exhaled nitric oxide in parts per billion (ppb) in patients with cystic fibrosis (CF; $\mathbf{0})$, primary ciliary dyskinesia (PCD) syndrome ( $\bullet$ ), and controls ( $\boldsymbol{\Delta})$ before (pre) as well as 20 min, 3 and $24 \mathrm{~h}$ after infusion of L-arginine. Every bar represents mean NO and SEM for the groups. ***: $\mathrm{p}<0.001$; **: $\mathrm{p}<0.01$; *: $\mathrm{p}<0.05$ versus baseline (Pre)

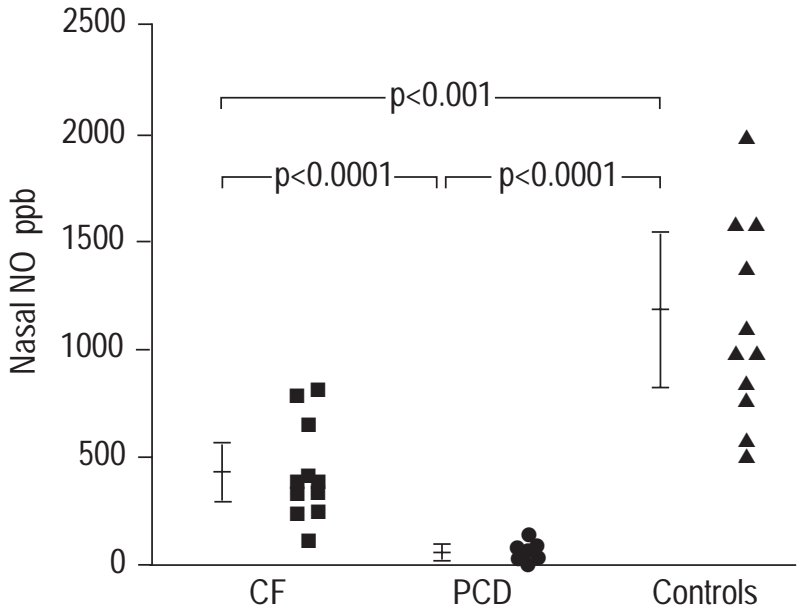

Fig. 3. - Nasal nitric oxide concentrations in parts per billion (ppb) in cystic fibrosis $(\mathrm{CF})$ patients, primary ciliary dyskinesia (PCD) syndrome patients, and controls. Concentrations in controls were significantly higher than in CF and PCD syndrome patients, but also lower in PCD syndrome when compared with $\mathrm{CF}$.

lower in CF (438.2 \pm 225.3 ; 95\% CI: 305-571.4 ppb), and lowest in PCD syndrome (72.1 \pm 46.4 ; $95 \%$ CI: $37.8-106.5$ $\mathrm{ppb}$ ). In controls nasal NO concentration was significantly increased immediately after the infusion of L-arginine and returned to baseline at $24 \mathrm{~h}$ (fig. 4). The same pattern was also observed for both $\mathrm{CF}$ and PCD syndrome patients (fig. 4). Nasal NO concentrations remained subnormal in both conditions, when compared with baseline concentrations in controls.

\section{Pulmonary function}

No significant changes in FEV1 or FVC were observed in any of the subjects during the study period.

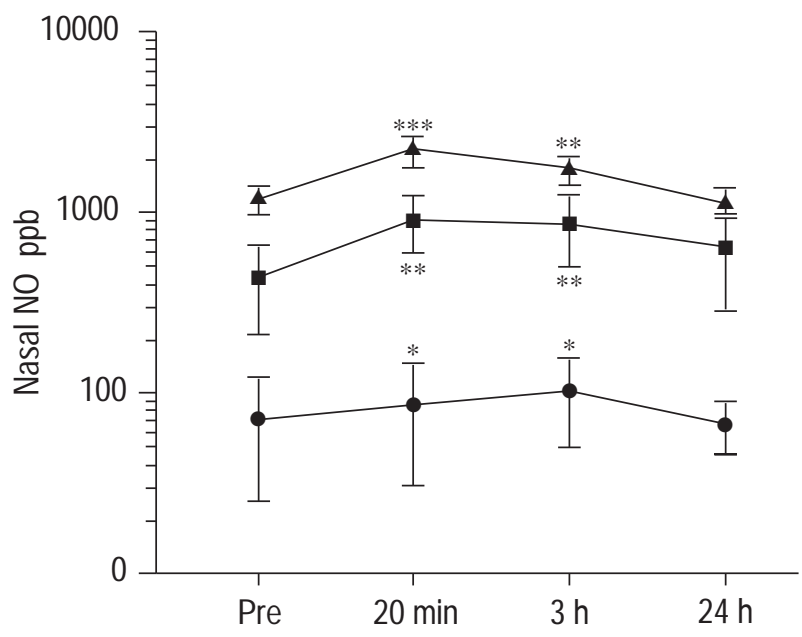

Fig. 4. - Nasal nitric oxide concentrations in parts per billion (ppb) in cystic fibrosis $(\mathrm{CF} ; \boldsymbol{-})$ patients, primary ciliary dyskinesia $(\mathrm{PCD} ; \bullet)$ syndrome patients, and controls $(\boldsymbol{\Delta})$ before and after infusion of Larginine. A significant increase was observed in all groups; ***: $\mathrm{p}<0.001 ; * *: \mathrm{p}<0.01 ; *: \mathrm{p}<0.05$ versus baseline (Pre). 


\section{Discussion}

These results confirm that NO concentrations in the upper and lower airways of CF and PCD syndrome patients are lower than in normal individuals. Although endogenous NO formation in CF and PCD syndrome patients could be increased significantly by administering the substrate of NO synthases, L-arginine, airway NO remained subnormal in both diseases. These findings provide further evidence for decreased NOS activity in both conditions and exclude substrate limitation as a reason for decreased NO formation in CF or PCD syndrome patients.

Low NO concentrations in CF could be both due to increased retention or decreased NO formation within the airways. It has recently been demonstrated that significant amounts of NO are degraded and retained in the epithelial lining fluid of children with lower respiratory tract infections [18] and in sputum of CF patients [14]. Retention is probably less important in the upper airways of $\mathrm{CF}$ patients where NO concentrations were also subnormal at baseline and remained decreased after infusion of L-arginine. These findings may, at least in part, be due to the fact that a major part of the upper airway NO is produced within the paranasal sinuses which do not communicate properly with the nasal cavities in $\mathrm{CF}$.

An alternative explanation for the impaired increase of airway NO concentration may be that the activity of NOS is reduced in the airways of $\mathrm{CF}$ patients. Evidence for impaired NOS activity in CF airways has been recently found by Kelley and Drumm [19]. They have described reduced airway nitrate/nitrite production in a murine $\mathrm{CF}$ model in response to lipopolysaccharide or L-arginine. Furthermore, they showed lower inducible NOS (NOS2) expression in lung tissue of these CF mice than wild type mice and could subsequently confirm these findings in excised tracheas from $\mathrm{CF}$ patients undergoing lung transplantation [19]. Decreased NOS activity in CF airways could be of clinical relevance since NO has antiviral and antibacterial properties $[20,21]$, and is important in the killing of Staphylococcus aureus, a common pathogen in $\mathrm{CF}$ lung disease [22]. In addition, recent studies suggest a NO-related modulation of ion transport $[23,24]$. Therefore, increasing NO levels may be of functional importance in CF.

Lower than normal airway NO concentrations in PCD syndrome were first described by LUNDBERG et al. [7] who reported decreased nasal NO levels in four children with Kartagener's syndrome. The present results demonstrate that not only upper but also lower airway NO concentrations are decreased in PCD syndrome. However, due to the marked overlap of lower airway NO concentrations between the groups, upper airway NO seems to be a better tool in the diagnosis of PCD syndrome. Since NO modulates ciliary beating frequency [1], low NO concentrations could contribute to the impaired mucociliary clearance in these patients. As discussed before, reduced lower airway $\mathrm{NO}$ concentrations may also be due to retention of NO in airway fluids. Retention is, however, unlikely to explain the decreased NO concentrations in the nose of PCD syndrome patients which were significantly lower than in normals or CF patients. Both PCD syndrome and CF patients have poor communication of the nasal cavity with the paranasal sinuses which produce large amounts of NO. This phenomenon alone cannot explain why NO concen- trations in the upper airways of PCD syndrome patients are lower than in CF and display little increase after stimulation with L-arginine. Therefore, the present data provide further evidence for decreased or defective NO formation in PCD syndrome patients.

NO is a powerful endogenous and exogenous vasodilator $[1,25]$. Autoinhalation of nasally derived NO at concentrations of $304 \pm 19 \mathrm{ppb}$ had been shown to improve arterial oxygenation, presumably as a result of changes in the ventilation-perfusion ratio [13]. Inspired NO also reduces pulmonary bronchoconstriction in response to methacholine provocation [26-28], but has no effect on airway resistance in normal subjects [27]. Interestingly, inhaled NO mediates significant bronchodilation in asthmatic patients without induced bronchoconstriction only at high concentrations (80 parts per million) [27]. Asthmatics have increased NO concentrations in their expired air, but they also have increased bronchomuscular tone. Although the source of exhaled NO is unknown, it is assumed that increased exhaled NO levels in asthmatics are due to the observed overexpression of NOS2 in the airway epithelial cells of these patients [29]. NO that is produced in the epithelial cells, similar to inhaled NO, may not reach the important elements in the bronchi which regulate bronchomotor tone, and this could be due to the known very short biological half-life of NO [30]. Systemically administered L-arginine could potentially reach these elements (e.g. constitutive isoforms of NOS in smooth muscles or nerve fibres) and thereby relax airway smooth muscle cells. However, no improvement of pulmonary function was observed in CF or PCD syndrome patients.

In conclusion, these results demonstrate that infusion of L-arginine increases airway nitric oxide concentration in normals, cystic fibrosis, and primary ciliary dyskinesia patients. However, despite the significant increase of nasal and exhaled nitric oxide in cystic fibrosis and primary ciliary dyskinesia, airway nitric oxide concentrations remained subnormal in these conditions. This may be one of the reasons why no effect was observed on pulmonary function in these patient groups.

\section{References}

1. Barnes PJ, Belvisi MG. Nitric oxide and lung disease. Thorax 1993; 48: 1034-1043.

2. Asano K, Chee CBE, Gaston B, et al. Constitutive and inducible nitric oxide synthase gene expression, regulation, and activity in human lung epithelial cells. Proc Natl Acad Sci USA 1994; 91: 10089-10093.

3. Kobzik L, Bredt DS, Lovenstein CJ, et al. Nitric oxide synthase in human and rat lung: immunocytochemical and histochemical localization. Am J Respir Cell Mol Biol 1993; 9: 371-377.

4. Fischer A, Hoffmann B. Nitric oxide syntheses in neurons and nerve fibers of lower airways and in vagal sensory ganglia of man. Correlation with neuropeptides. $\mathrm{Am} \mathrm{J}$ Respir Crit Care Med 1996; 154: 209-216.

5. Kharitonov SA, Wells AU, O'Connor BJ, Hansell DM, Cole PJ, Barnes PJ. Elevated levels of exhaled nitric oxide in bronchiectasis. Am J Respir Crit Care Med 1995; 151: 1889-1893.

6. Alving K, Weitzberg E, Lundberg JM. Increased amount of nitric oxide in exhaled air of asthmatics. Eur Respir $J$ 1993; 6: 1368-1370. 
7. Lundberg JON, Weitzberg E, Nordvall SL, Kuylenstierna R, Lundberg JM, Alving K. Primarily nasal origin of exhaled nitric oxide and absence in Kartagener's syndrome. Eur Respir J 1994; 7: 1501-1504.

8. Balfour-Lynn IM, Laverty A, Dinwiddie R. Reduced upper airway nitric oxide in cystic fibrosis. Arch Dis Child 1996; 75: 319-322.

9. Grasemann H, Michler E, Wallot M, Ratjen F. Decreased concentrations of exhaled nitric oxide (NO) in patients with cystic fibrosis. Ped Pulmonol 1997; 24: 173-177.

10. Kharitonov SA, Cailes JB, Black CM, du Bois RM, Barnes PJ. Decreased nitric oxide in the exhaled air of patients with systemic sclerosis with pulmonary hypertension. Thorax 1997; 52: 1051-1055.

11. Boat TF. Cystic fibrosis. In: Behrman RE, Kliegman RM, Arvin AM, eds. Nelson Textbook of Pediatrics, 15th Edn. Philadelphia, WB Saunders, 1996; pp. 1239-1250.

12. Boat TF. Primary ciliary dyskinesia. In: Behrman RE, Kliegman RM, Arvin AM, eds. Nelson Textbook of Pediatrics, 15th Edn. Philadelphia, WB Saunders, 1996;p. 1251.

13. Lundberg JON, Settergren G, Gelinder S, Lundberg JM, Alving K, Weitzberg E. Inhalation of nasally derived nitric oxide modulates pulmonary function in humans. Acta Physiol Scand 1996; 158: 343-347.

14. Grasemann H, Ioannidis I, Tomkiewicz RP, de Groot H, Rubin BK, Ratjen F. Nitric oxide metabolites in cystic fibrosis lung disease. Arch Dis Child 1998; 78: 49-53.

15. Högman M, Stromberg S, Schedin U, Frostell CG, Hedenstierna G, Gustafsson E. Nitric oxide from the human respiratory tract efficiently quantified by standardized single breath measurements. Acta Physiol Scand 1997; 159: 345346.

16. van der Hardt $H$, Nowak-Beneke R. Lung volumes in healthy boys and girls $6-15$ yrs of age. Lung 1976; 154: 51-63.

17. Quanjer PH, Tammeling GJ, Cotes JE, Pedersen OF, Peslin R, Yernault JC. Lung volumes and forced ventilatory flows. Eur Respir J 1993; 6: Suppl. 16, 5-40.

18. Grasemann H, Ioannidis I, de Groot H, Ratjen F. Metabolites of nitric oxide in the lower respiratory tract of children. Eur J Pediat 1997; 156: 575-578.
19. Kelley TJ, Drumm ML. Inducible nitric oxide synthase is reduced in cystic fibrosis murine and human epithelial cells. J Clin Invest 1998; 102: 1200-1207.

20. Nathan CP, Hibbs JB. Role of nitric oxide synthesis in macrophage antimicrobial activity. Curr Opin Immunol 1991; 3: 65-70.

21. Liew FY, Cox FF. Nonspecific resistance mechanisms: the role of nitric oxide. Immunol Today 1991; 12: A17A21.

22. Malawista SE, Montgomery RR, van Blaricom G. Evidence for reactive nitrogen intermediates in killing of staphylococci by human neutrophil cytoplasts. $J$ Clin Invest 1992; 90: 631-636.

23. Dong YJ, Chao AC, Konyama K, et al. Activation of CFTR chloride current by nitric oxide in human T lymphocytes. EMBO J 1995; 14: 2700-2707.

24. Kamosinska B, Radomski MW, Duszyk M, Radomski A, Man FS. Nitric oxide activates chloride currents in human lung epithelial cells. Am J Physiol 1997; 272: L1098L1104.

25. Frostell C, Fratacci M-D, Wain JC, Zapol WM. Inhaled nitric oxide: a selective pulmonary vasodilator reversing hypoxic pulmonary vasoconstriction. Circulation 1991; 83: 2038-2047.

26. Högman M, Frostell CG, Arnberg H, Hedenstierna G. Inhalation of nitric oxide modulates methacholine-induced bronchoconstriction in the rabbit. Eur Respir $J$ 1993; 6: 177-180.

27. Högman M, Frostell C, Hedenström H, Hedenstierna G. Inhalation of nitric oxide modulates adult human bronchial tone. Am Rev Respir Dis 1993; 148: 14741478.

28. Dupuy PM, Shore SA, Drazen JM, Frostell C, Hill WA, Zapol WM. Bronchodilator action of inhaled nitric oxide in guinea pigs. J Clin Invest 1992; 90: 421-428.

29. Hamid Q, Springall DR, Riveros-Moreno V, et al. Induction of nitric oxide synthase in asthma. Lancet 1993; 342: $1510-1513$.

30. Gaston B, Drazen JM, Loscalzo J, Stamler JS. The biology of nitrogen oxides in the airways. Am J Respir Crit Care Med 1994; 149: 538-551. 